\title{
Catalytic Oxidation of Carbon Monoxide at Cryogenic Temperatures
}

\author{
Ilkeun Lee and Francisco Zaera* \\ Department of Chemistry, University of California, Riverside, CA 92521, USA \\ Email: zaera@ucr.edu
}

\begin{abstract}
Although solid gold is often considered chemically inert, it has been shown that, in the form of nanometer-size particles, it is capable of promoting many catalytic reactions. This behavior is typified by the ease with which catalysts made out of gold nanoparticles dispersed on titania supports oxidize carbon monoxide to carbon dioxide around room temperature. Here we report on a unique gold/titania-based catalyst that, in addition to such room-temperature catalysis, displays a second active regime at much lower temperatures, as low as $120 \mathrm{~K}$. We show that this new catalytic regime follows a mechanism different to that operative at room temperature, involving at least two titania-adsorbed $\mathrm{CO}$ species and a synergy between the uptake of $\mathrm{CO}$ and $\mathrm{O}_{2}$ on the surface. New titanate sites, formed upon treatment of catalysts made out of dispersing Au nanoparticles on amorphous titania with $\mathrm{NaOH}$, appear to be responsible for the opening of this new reaction channel.
\end{abstract}

Keywords: Carbon Monoxide Oxidation, Heterogeneous Catalysis, Gold, Titania, Infrared Absorption Spectroscopy, Cryogenic Temperatures

(C) 2014. This manuscript version is made available under the Elsevier user license http://www.elsevier.com/open-access/userlicense/1.0/ 


\section{Introduction}

Much excitement has been generated in recent years by the discovery that gold, when dispersed as nanoparticles on certain high-surface-area supports, can be quite active in promoting many reactions under mild conditions, usually around room temperature [1]. The oxidation of carbon monoxide in particular has been used as a prototypical example to show the potential of gold in catalysis [2, 3]. Extensive discussion has been reported on the mechanistic details of that reaction [4-7], and samples have been identified capable of catalytically promoting such oxidation at temperatures as low as $200 \mathrm{~K}[2,5,8]$, However, in all reported cases, to the best of our knowledge, these oxidation reactions have been shown to be activated, with significant catalytic activity starting only at moderate ( room) temperatures. Here we report on a unique case where the steady catalytic rate of oxidation for carbon monoxide increases again at lower temperatures, all the way down to $120 \mathrm{~K}$ (the lowest temperature we were able to achieve with our experimental setup), and displays an unusual apparent negative activation energy. Cryogenic catalysis such as this is rather uncommon, and typically seen only for more esoteric cases such as the interconversion between ortho and para hydrogen. We argue that the behavior observed here is the consequence of a change in the mechanism of the reaction: the way this cryogenictemperature reaction proceeds is different than in the other reported cases. Below we discuss the requirements in terms of both the properties of the catalyst and the surface reaction intermediates involved for the cryogenic oxidation to occur.

\section{Experimental Details}


Our catalyst exhibiting this unique cryogenic activity is based on gold nanoparticles dispersed on an amorphous titania support made by sol-gel chemistry and modified via treatment with sodium hydroxide $\left(\mathrm{Au} / \mathrm{TiO}_{2}(\mathrm{~A})+\mathrm{NaOH}\right)$. Details of the synthesis of this and other reference catalysts are provided in the Supporting Information. The activity of all catalysts was evaluated by following in situ both the consumption of carbon monoxide and the accumulation of carbon dioxide during the conversion of mixtures of $\mathrm{CO}$ and $\mathrm{O}_{2}$ versus reaction time using diffuse reflectance infrared absorption spectroscopy (DRIFTS). Details on the procedures used for the calibration of the DRIFTS signals and the calculations of reaction rates are also provided in the Supporting Information (Figures S1 and S2).

\section{Results}

The DRIFTS traces recorded in these studies, exemplified in Figure 1, are complex, and display a multitude of features covering several frequency ranges. Fortunately, these systems have been studied extensively in the past, and most of the DRIFTS peaks have been identified already. For one, carbonate and formate species are detected in the frequency range between 1300 and 1800 $\mathrm{cm}^{-1}$ (brown-shaded area in Figure 1) [9-11], and hydroxo surface moieties are responsible for the signals in the $3500-3800 \mathrm{~cm}^{-1}$ window (purple-shaded area) $[12,13]$. These DRIFTS signatures were found to be different in the cryogenically-active catalyst versus the other reference samples (Figure 2), indicating that the surface species observed in the spectroscopic experiments are intrinsically associated with each catalyst. On the other hand, the associated 
species were found not to change in nature either during or after reaction, an observation that suggests that they do not participate directly in the cryogenic-temperature CO-oxidation reaction. The main information relevant to the cryogenic oxidation reaction was extracted from the DRIFTS peaks associated with carbon monoxide, seen in the $\sim 2000-2250 \mathrm{~cm}^{-1}$ range (blueshaded area in Figure 1), and with carbon dioxide, observed in the $2300-2400 \mathrm{~cm}^{-1}$ window (redshaded area).

The kinetics of the CO-to- $\mathrm{CO}_{2}$ conversion was followed by using the integrated signal intensities of the corresponding $\mathrm{CO}$ and $\mathrm{CO}_{2}$ DRIFTS peaks. A typical plot of the time-dependent evolution of those intensities, after conversion into number of moles, is shown in Figure 3a (details of the DRIFTS signal calibration and rate calculation procedures are provided in the Supporting Information), and the raw data for all the runs with all the samples used in this study are provided in Figures 4 and 5. Analysis of these kinetic data turned out to not be simple in the cryogenic temperature regime, because condensation of the $\mathrm{CO}_{2}$ produced by the reaction inside the pores of the catalysts interferes with the DRIFTS measurements. As a consequence, many of the kinetic traces display two time regimes, a fast transient possibly reflecting the initial gas condensation process, and a subsequent slower steady evolution due to the CO conversion (Figures 4 and 5). Regardless, the cryogenic oxidation of $\mathrm{CO}$ with the $\mathrm{Au} / \mathrm{TiO}_{2}(\mathrm{~A})+\mathrm{NaOH}$ catalyst is evidenced by both the decrease in the amount of $\mathrm{CO}$ (blue and green traces in Figure 3a) and the increase in the amount of $\mathrm{CO}_{2}$ (red) detected by the DRIFTS signals as a function of reaction time. The $\mathrm{CO}_{2}$ DRIFTS feature does saturate after about approximately $1 \mathrm{~h}$ of reaction, likely because of the preferential absorption of that gas inside the pores of the catalyst, and therefore diverges from the values measured for the CO DRIFTS peaks at longer times. In order 
to avoid errors due to this gas condensation while also minimizing any experimental artifacts due to the initial transient regime, turnover frequencies (TOFs, in $\mathrm{CO}$ molecules converted per gold surface atom per second) for the steady conversion regime were calculated by estimating the slope of the signal intensity-versus-time DRIFTS curves for $\mathrm{CO}_{2}$ (because those were less noisy than the ones for $\mathrm{CO}$ ) after $1 \mathrm{~h}$ of reaction. This choice may be somewhat arbitrary, but in any case the qualitative differences in cryogenic catalytic behavior between the $\mathrm{Au} / \mathrm{TiO}_{2}(\mathrm{~A})+\mathrm{NaOH}$ catalyst and the rest of the samples, the main observation reported here, is evident even in the raw data (Figures 4 and 5). It should be pointed out that, in spite of the limitations encountered with the quantitation of the DRIFTS signals in the experiments carried out at cryogenic temperatures, we believe that this technique is still better suited than others such as gas chromatography for these studies, because the condensation of the $\mathrm{CO}_{2}$ produced means that it can not be detected in the gas phase.

TOF data for the oxidation of carbon monoxide with $\mathrm{O}_{2}$ were acquired between 120 and $350 \mathrm{~K}$ with all of our catalysts. The results obtained with the main catalyst, a 1 wt $\% 15-\mathrm{nm}$ $\mathrm{Au} / \mathrm{TiO}_{2}(\mathrm{~A})$ sample treated with $\mathrm{NaOH}$, are shown as red solid squares in Figure 3b. This catalyst shows the same type of activated catalytic performance toward the oxidation of $\mathrm{CO}$ around room temperature seen with other $\mathrm{Au} / \mathrm{TiO}_{2}$-based catalysts, as shown in Figures $3 \mathrm{c}, 4$, and 5. In addition, though, it also displays a second regime of high catalytic activity at cryogenic temperatures, as mentioned already, with significant TOFs resurging below approximately 250 K. High TOFs were in fact measured all the way down to $120 \mathrm{~K}$, the lowest temperature available with our instrumentation. This difference in behavior is clearly observable in the raw DRIFTS kinetic data shown in Figures 4 and 5. For instance, the consumption of CO over time 
in reactions carried at $120 \mathrm{~K}$ is seen only with the $\mathrm{Au} / \mathrm{TiO}_{2}(\mathrm{a})+\mathrm{NaOH}$ catalyst. Regardless of any experimental limitations in the quantitative estimation of the TOFs of the low-temperature oxidation reaction discussed above, there is a clear qualitative difference in the behavior of this catalyst as compare to the all reference samples used in our study. The activity seen with our catalyst in this second temperature regime has, to the best of knowledge, not been matched by any other reported catalyst; it is the key result of this report.

Additional spectroscopic and kinetic studies were performed with a number of reference catalysts in an attempt to systematically isolate the specific characteristics that make the $\mathrm{Au} / \mathrm{TiO}_{2}(\mathrm{~A})+\mathrm{NaOH}$ catalyst active under cryogenic temperatures. Eight different catalysts were prepared and tested, namely:
a. $1 \mathrm{wt} \% \mathrm{Au} / \mathrm{TiO}_{2}(\mathrm{~A})+\mathrm{NaOH}$,
b. $\mathrm{TiO}_{2}(\mathrm{~A})+\mathrm{NaOH}$,
c. $1 \mathrm{wt} \% \mathrm{Pt} / \mathrm{TiO}_{2}(\mathrm{~A})+\mathrm{NaOH}$.
d. $1 \mathrm{wt} \% \mathrm{Au} / \mathrm{TiO}_{2}-\mathrm{P} 25$,
e. $1 \mathrm{wt} \% \mathrm{Au} / \mathrm{TiO}_{2}-\mathrm{P} 25+\mathrm{NaOH}$,
f. $1 \mathrm{wt} \% \mathrm{Au} / \mathrm{TiO}_{2}(\mathrm{~A})$,
g. $1 \mathrm{wt} \% \mathrm{Au} / \mathrm{TiO}_{2}(\mathrm{~A})+\mathrm{NaOH}+\mathrm{HCl}$, and
h. $1 \mathrm{wt} \% \mathrm{Au} / \mathrm{Na}_{2} \mathrm{Ti}_{3} \mathrm{O}_{7}$.

All these samples were fully characterized, and proved to be similar in nature except for the specific parameter varied in each case with respect to the others, as discussed below. The CO 
oxidation TOF data obtained with these samples are summarized in Figures $3 b$ and $3 c$, and the raw kinetic data provided in Figures 4 and 5. The following required surface elements were identified for cryogenic catalytic activity:

1. Gold in the form of nanoparticles dispersed on the titania support. No samples based on pure titania, not even after $\mathrm{NaOH}$ treatment (Sample b; Figure 3b, brown open downward triangles), nor catalysts where Au is replaced by Pt (Sample c; Figure 3c, brown solid downward triangles), display any measurable oxidation catalytic activity (within our experimental error) at temperatures below $\sim 250 \mathrm{~K}$. The role of this gold phase is likely to be to facilitate the low-temperature activation of molecular oxygen, possibly at the $\mathrm{Au}$ $\mathrm{TiO}_{2}$ interface $[6,7,14,15]$, given that it has been shown in surface-science studies that $\mathrm{CO}$ can be oxidized by atomic oxygen adsorbed on gold nanoclusters at temperatures as low as $35 \mathrm{~K}[16,17]$. It should also be mentioned that, although there have been suggestions in the literature that the active gold phase may consist of partially-charged $\mathrm{Au}$ atoms [18, 19], no evidence of such species was seen in X-ray photoelectron spectroscopy (XPS) data from our samples (Figure $6 \mathrm{a}$ ): only the $4 \mathrm{f}_{7 / 2}$ and $4 \mathrm{f}_{5 / 2}$ XPS peaks for metallic gold [20, 21], at 83.5 and $87.05 \mathrm{eV}$ respectively, were observed in all cases (some gold loss seems to take place upon treatment with $\mathrm{NaOH}$ and $\mathrm{HCl}$, possibly from the outside of the pores of the support). The lack of any shifts in the Au $4 \mathrm{f}$ peaks upon $\mathrm{NaOH}$ treatment of the sample also argues against the formation of $\mathrm{Au}-\mathrm{Na}$ intermetallic mixtures. Finally, it is surprising that our catalysts show oxidation activity in spite of the large size $(\sim 15 \mathrm{~nm})$ of the gold nanoparticles used, given that most past studies report optimal activity in a nanoparticle diameter range of a few nanometers [2, 4]. Preliminary 
data from our laboratory suggest that, indeed, smaller Au nanoparticles can lead to faster cryogenic oxidation rates.

2. Titania in amorphous form. Similar gold catalysts made with crystalline $\mathrm{TiO}_{2}-\mathrm{P} 25$ (the standard 80:20 anatase:rutile Degussa formulation used in most studies with titaniabased catalysts) display virtually no cryogenic-temperature activity, within our experimental error, either before or after treatment with $\mathrm{NaOH}$ (Samples d and e; solid blue circles and open red squares in Figure 3c, respectively), and the same is true with $\mathrm{Au} @ \mathrm{TiO}_{2}$ yolk-shell catalysts made with pure anatase (data not shown). This observation points to the participation of defect sites within the oxide in the mechanism of the reaction. The small activity seen below $250 \mathrm{~K}$ in Figure $3 \mathrm{c}$ for some of these samples may reflect the presence of a few surface defects in the corresponding solids, similar to those present in the $\mathrm{Au} / \mathrm{TiO}_{2}(\mathrm{~A})+\mathrm{NaOH}$ catalyst.

3. A surface treated with sodium hydroxide. Indeed, significant cryogenic activity was seen with Sample a (Figure 3b, solid red squares) but not with Sample f (Figure 3b, open blue circles). This is the novel addition to the synthesis of our samples that makes them unique and leads to their unprecedented cryogenic-temperature activity. The $\mathrm{NaOH}$ treatment may make the surface more basic, a change that has been reported in the past as a way to induce higher low-temperature catalytic activity [22]. Alternatively (or concurrently), it appears to lead to the creation of new catalytically active titanate sites on the surface of the catalyst. The formation of titanate species upon treatment of titania with sodium hydroxide is well established [23], and it is evidenced in the XPS data in 
Figures $6 \mathrm{~b}$ and $6 \mathrm{c}$ by the new $\mathrm{Ti} 2 \mathrm{p}_{3 / 2}$ peak that develops at $459.1 \mathrm{eV}$ (with either amorphous or crystalline - $\mathrm{P} 25$ - forms). The possibility of the addition of impurities to the samples during their treatment with $\mathrm{NaOH}$, an alternative way to explain their cryogenic catalytic activity, was ruled out by XPS, since no elements other that Ti, O, $\mathrm{Au}$, and $\mathrm{Na}$ (and a small amount of adventitious carbon due to sample handling) were ever detected. Moreover, the sodium seen in the XPS data of the $\mathrm{NaOH}$-treated samples was always in the form of ionic $\mathrm{Na}^{+}$, and displayed spectra similar to that from sodium titanate (Figure S3). We believe that this sodium is associated with terminal $\mathrm{Ti}^{-}-\mathrm{O}^{-}-\mathrm{Na}^{+}$ surface sites, product of ion exchange at the Ti-OH moieties of our amorphous titania during the $\mathrm{NaOH}$ treatment. The $\mathrm{Na}^{+}$can be easily removed by $\mathrm{HCl}$ (Figure $\mathrm{S} 3$ ).

A couple of additional observations can be derived from the data in Figures 3 and 6: (a) the formation of the active titanate species is reversible: subsequent treatment with $\mathrm{HCl}$ removes those species from the surface (XPS evidence in Figure 6), and suppresses the cryogenictemperature activity of the catalyst toward CO oxidation (Sample g; solid green upward-pointing triangles in Figure 3b); and (b) the titanate sites must be amorphous for the cryogenic catalysis to occur, because titanate-containing catalysts made either by treating P25 titania with $\mathrm{NaOH}$ (Sample e; Figure 3c, open red squares) or by using crystalline $\mathrm{Na}_{2} \mathrm{Ti}_{3} \mathrm{O}_{7}$ (Sample h; Figure 3c, open green upward-pointing triangles) do not display much cryogenic catalytic activity. It is difficult to establish the exact nature of the active site in these amorphous titanate-based samples, but we speculate that the unique cryogenic catalytic activity may be associated with the titanium atoms that display the modified electronic structure highlighted in the XPS data, since the 
adsorbed CO species seen in DRIFTS are believed to bind to titanium centers within the titania $[24,25]$.

The mechanism of this new cryogenic-temperature $\mathrm{CO}$ oxidation reaction was explored further by DRIFTS. A couple of kinetic differences between the cryogenic and room-temperature catalytic regimes were identified:

1. The time evolution of the $\mathrm{CO}$ and $\mathrm{CO}_{2}$ signals during the catalytic oxidation reaction is clearly different between the two temperature regimes, and the detection of cryogenic reactivity unique to the $\mathrm{Au} / \mathrm{TiO}_{2}(\mathrm{~A})+\mathrm{NaOH}$ sample, as made clear by the raw kinetic data provided in Figures 4 and 5.

2. $\mathrm{CO}_{2}$ can be produced at $120 \mathrm{~K}$, but not at $300 \mathrm{~K}$, by sequentially exposing the catalyst to $\mathrm{CO}$ and then to $\mathrm{O}_{2}$ (pumping the system in between), an indication that a weakly adsorbed $\mathrm{CO}$ species can be retained on the surface under cryogenic conditions (Figure 7). The reverse $\mathrm{O}_{2}-\mathrm{Pump}-\mathrm{CO}$ sequence fails to produce significant amounts of $\mathrm{CO}_{2}$; no equivalent weakly-adsorbed $\mathrm{O}_{2}$ species appears to form in these systems.

Our in-situ DRIFTS studies of the adsorbed species during the $120 \mathrm{~K} \mathrm{CO}$ oxidation also point to a complex sequence of steps involving at least two adsorbed CO species:

1. An initial CO-titania species manifested in the DRIFTS traces by a sharp peak that grows around $2180 \mathrm{~cm}^{-1}$ when $\mathrm{O}_{2}$ is added to the cell in $\mathrm{CO}-\mathrm{Pump}-\mathrm{O}_{2}$ experiments (Figure $8 \mathrm{a}$ ). 
The fact that this species is eventually oxidized to $\mathrm{CO}_{2}$ is suggested by the inverse correlation seen between the time evolution of the $2180 \mathrm{~cm}^{-1}$ CO DRIFTS signal intensity (blue trace in Figure 8b) and that for the feature at $2350 \mathrm{~cm}^{-1}$ corresponding to $\mathrm{CO}_{2}$ (red trace): after the initial appearance of the $2180 \mathrm{~cm}^{-1}$ CO-titania species in the spectra, its intensity decreases monotonically as more $\mathrm{CO}_{2}$ is produced. More interestingly, the 2180 $\mathrm{cm}^{-1}$ DRIFTS peak intensity (again, the blue trace in Figure $8 \mathrm{~b}$ ) follows closely the trace for the $\mathrm{CO}_{2}$ TOF versus time (green trace), calculated by taking the derivative of the $\mathrm{CO}_{2}$ DRIFTS signal (red trace) with respect to time. In kinetic terms, such correlation suggests relatively simple first-order $\mathrm{CO}_{2}$ formation kinetics with respect to the surface coverage of the $2180 \mathrm{~cm}^{-1} \mathrm{CO}-\mathrm{TiO}_{2}$ species, although some deviations are clearly seen in the initial stages of the reaction, when other mechanistic steps may be rate limiting. Notice that, in contrast, no correlation at all could be identified between the catalytic activity $\left(\mathrm{CO}_{2} \mathrm{TOF}\right.$, red trace) and the intensity of the DRIFTS peak due to $\mathrm{CO}$ adsorbed on the gold surface (purple trace, labeled $\mathrm{CO}-\mathrm{Au}$, from the DRIFTS peak centered at approximately $2110 \mathrm{~cm}^{-1}$. This peak is quite weak and difficult to see in Figure 8a; its intensity has been magnified by a factor of 20 in Figure 8b). The latter observation indicates that such Au-adsorbed $\mathrm{CO}$ species do not play a direct role in the cryogenic oxidation reaction (as already suggested by Yates et al. [7]). Also, our evidence points to the $2180 \mathrm{~cm}^{-1} \mathrm{CO}-\mathrm{TiO}_{2}$ species being formed on the surface of the titania support, not on the titania-gold interface as proposed previously [26-28]: the same species is also seen on Au catalysts made out of $\mathrm{TiO}_{2}-\mathrm{P} 25$, with and without $\mathrm{NaOH}$ treatment, and, to a lesser extent, on pure titania, in the absence of gold nanoparticles (Figure 9). In fact, some $\mathrm{CO}_{2}$ can be made at $120 \mathrm{~K}$ with all of the $\mathrm{Au} / \mathrm{TiO}_{2}$ catalysts studied here under the sequential 
CO-Pump- $\mathrm{O}_{2}$ experimental modality (Figure $8 \mathrm{c}$ ), although, of course, not in a sustained catalytic fashion.

2. A second CO-titania intermediate, evident in the in-situ DRIFTS data obtained under steady catalytic conditions by a peak at approximately $2160 \mathrm{~cm}^{-1}$ (Figure 10a, 2nd-frombottom red trace). The lowering in frequency with respect to the previous species has been associated with $\mathrm{Ti}^{4+}$ centers having less Lewis acidity [24], and in our case could be related to the titanate centers. It is in the formation of this intermediate, most likely via diffusion of the first intermediate to a new site, that the $\mathrm{Au} / \mathrm{TiO}_{2}(\mathrm{~A})+\mathrm{NaOH}$ catalyst, which shows activity at cryogenic temperatures, shows a different behavior than the others: the transition from the $2180 \mathrm{~cm}^{-1}$ to the $2160 \mathrm{~cm}^{-1}$ site appears to occur to completion under reaction conditions on the cryogenic-temperature-active catalyst, whereas it seems to not be possible with any other catalyst (Figure 10a). Moreover, the exchange of $\mathrm{CO}$ surface sites associated with this transition must be assisted (or blocked) by oxygen, since it does not occur in the experiments were $\mathrm{CO}$ and $\mathrm{O}_{2}$ are dosed separately; witness the absence of any signal at $2160 \mathrm{~cm}^{-1}$ in the DRIFTS data from the CO-Pump- $\mathrm{O}_{2}$ experiments reported in Figure 8a upon the addition of oxygen. The fact that the $2160 \mathrm{~cm}^{-1}$ intermediate is consumed during the $\mathrm{CO}$ oxidation catalysis is suggested by the inverse correlation seen over time between its DRIFTS peak intensity and the production of $\mathrm{CO}_{2}$ (Figure 10b): the intensity of the feature at $2160 \mathrm{~cm}^{-1}$ (but not that at $2180 \mathrm{~cm}^{-1}$ ) decreases with reaction time, as the peak for $\mathrm{CO}_{2}$ grows. Because the population of this state also depends on the size of the Au nanoparticles (Figure 10c, which shows a selective increase in signal intensity for the $2160 \mathrm{~cm}^{-1}$ peak with 
increasing $\mathrm{Au}$ nanoparticle diameter), it can be envisioned that the final $\mathrm{CO}$ oxidation step occurs at the Au-titania interface, where $\mathrm{O}_{2}$ dissociation may be assisted by the second $\mathrm{CO}$ intermediate [7]: the footprint of the gold nanoparticles is expected to be larger as their diameter increases, hence the increase in $2160 \mathrm{~cm}^{-1}-\mathrm{CO}$ surface concentration indicated by the DRIFTS data (Figure 10c).

\section{Discussion and Conclusions}

Here, we have reported a new gold-titania catalyst capable of catalytically oxidizing carbon monoxide at record cryogenic temperatures. That catalyst is prepared by dispersing $\mathrm{Au}$ nanoparticles on a sol-gel-made amorphous titania support and treating the resulting material with $\mathrm{NaOH}$. New titanate sites in amorphous form appear to be key in the promotion of the lowtemperature catalysis. Based on the spectroscopic evidence provided above, it was concluded that a key aspect of the unique performance of our $\mathrm{Au} / \mathrm{TiO}_{2}(\mathrm{~A})+\mathrm{NaOH}$ catalyst is the existence of a synergistic effect between the adsorption of $\mathrm{CO}$ and oxygen, which affects the ease with which the required final $\mathrm{CO}$ intermediate state becomes accessible at cryogenic temperatures. We suggest that the role of the new titanate sites is to allow for the diffusion of the adsorbed CO from the titania adsorption sites to the gold-titania interface, where the final $\mathrm{CO}_{2}$ production step takes place. This idea is represented schematically in Figure 11.

Many gold-based catalysts have been reported in the past that display oxidation activity at socalled low temperatures [1, 29], which most authors mean to indicate values around room 
temperature. Our catalyst shows similar behavior in that temperature range, but also a second catalytic regime at much lower temperatures, as low as $120 \mathrm{~K}$. It should be indicated that there have been a handful of reports, including some early publications by Haruta and coworkers [2, 8], of catalysts active at intermediate temperatures between 120 and $300 \mathrm{~K}$, but in all those cases the reaction appears to follow similar reaction mechanisms. Moisture has also been suggested to play an important role in the promotion of oxidation reactions with gold-based catalysts [22, 30], but that does not appear to be a critical factor in the cryogenic catalysis reported here, because water was not detected by DRIFTS either in the gas phase or condensed on the surface at any stage of the reactions. Also, although significantly different behavior was observed in the hydroxo region of the spectra with the different samples studied, none suggest any correlation of the concentration of those groups on the surface with catalytic activity (Figure 2). Instead, with our $\mathrm{Au} / \mathrm{TiO}_{2}(\mathrm{~A})+\mathrm{NaOH}$ catalyst, the two temperature regimes where catalysis is observed display significantly different behavior, and appear to follow different reaction mechanisms. We believe that it is a combination of new defective titanate sites and their effect on the kinetics of the synergistic $\mathrm{CO}+\mathrm{O}_{2}$ adsorption that leads to the opening of the new cryogenic-temperature oxidation channel.

\section{Acknowledgements}

Funding for this project was provided by a grant from the U. S. Department of Energy, Office of Basic Sciences (Grant DOE-FG02-09ER16096). The XPS instrument used in this research was 
acquired with funds from the U. S. National Science Foundation, Grant DMR-0958796. We also like to thank Dr. Ji Bong Joo for his help with the synthesis of some of the catalyst. 


\section{References}

[1] G.J. Hutchings, and M. Haruta, Appl. Catal. A 291 (2005) 2.

[2] M. Haruta, N. Yamada, T. Kobayashi, and S. Iijima, J. Catal. 115 (1989) 301.

[3] G.C. Bond, C. Louis, and D.T. Thompson, Catalysis by Gold. Imperial College Press, World Scientific Publishing, London, 2006, 384.

[4] M. Valden, X. Lai, and D.W. Goodman, Science 281 (1998) 1647.

[5] F. Boccuzzi, A. Chiorino, M. Manzoli, P. Lu, T. Akita, S. Ichikawa, and M. Haruta, J. Catal. 202 (2001) 256.

[6] M.M. Schubert, S. Hackenberg, A.C. van Veen, M. Muhler, V. Plzak, and R.J. Behm, J. Catal. 197 (2001) 113.

[7] I.X. Green, W. Tang, M. Neurock, and J.T. Yates, Science 333 (2011) 736.

[8] M. Haruta, T. Kobayashi, H. Sano, and N. Yamada, Chem. Lett. 16 (1987) 405.

[9] A.M. Turek, I.E. Wachs, and E. DeCanio, J. Phys. Chem. 96 (1992) 5000.

[10] Y. Denkwitz, B. Schumacher, G. Kučerová, and R.J. Behm, J. Catal. 267 (2009) 78.

[11] M.C. Raphulu, J. McPherson, E. Lingen, J.A. Anderson, and M.S. Scurrell, Gold Bull. 43 (2010) 21.

[12] M.I. Zaki, and H. Knözinger, Mater. Chem. Phys. 17 (1987) 201.

[13] J.A. Toledo-Antonio, S. Capula, M.A. Cortés-Jácome, C. Angeles-Chávez, E. LópezSalinas, G. Ferrat, J. Navarrete, and J. Escobar, J. Phys. Chem. C 111 (2007) 10799.

[14] L. Molina, M. Rasmussen, and B. Hammer, J. Chem. Phys. 120 (2004) 7673.

[15] B.K. Min, and C.M. Friend, Chem. Rev. 107 (2007) 2709. 
[16] T.S. Kim, J.D. Stiehl, C.T. Reeves, R.J. Meyer, and C.B. Mullins, J. Am. Chem. Soc. 125 (2003) 2018.

[17] J. Kim, Z. Dohnálek, and B.D. Kay, J. Am. Chem. Soc. 127 (2005) 14592.

[18] R.J. Davis, Science 301 (2003) 926.

[19] J. Guzman, and B.C. Gates, J. Am. Chem. Soc. 126 (2004) 2672.

[20] S. Arrii, F. Morfin, A.J. Renouprez, and J.L. Rousset, J. Am. Chem. Soc. 126 (2004) 1199.

[21] J.-Y. Tsai, J.-H. Chao, and C.-H. Lin, J. Mol. Catal. A 298 (2009) 115.

[22] D.A.H. Cunningham, W. Vogel, and M. Haruta, Catal. Lett. 63 (1999) 43.

[23] D.V. Bavykin, J.M. Friedrich, A.A. Lapkin, and F.C. Walsh, Chem. Mater. 18 (2006) 1124.

[24] G. Cerrato, L. Marchese, and C. Morterra, Appl. Surf. Sci. 70-71 (1993) 200.

[25] I.X. Green, W. Tang, M. Neurock, and J.T. Yates Jr, Science 333 (2011) 736.

[26] G.C. Bond, and D.T. Thompson, Catal. Rev.-Sci. Technol. 41 (1999) 319.

[27] H. Klimev, K. Fajerwerg, K. Chakarova, L. Delannoy, C. Louis, and K. Hadjiivanov, J. Mater. Sci. 42 (2007) 3299.

[28] F. Vindigni, M. Manzoli, A. Chiorino, and F. Boccuzzi, Gold Bull. 42 (2009) 106.

[29] D. Widmann, Y. Liu, F. Schüth, and R.J. Behm, J. Catal. 276 (2010) 292.

[30] M. Daté, and M. Haruta, J. Catal. 201 (2001) 221. 


\section{Figure Captions}

Figure 1. Typical diffuse-reflectance infrared absorption spectroscopy (DRIFTS) data used to characterize the performance of our gold-titania catalysts for the conversion over time of a mixture of 200 Torr $\mathrm{CO}+200$ Torr $\mathrm{O}_{2}$ at $120 \mathrm{~K}$. The catalyst consists of $1 \mathrm{wt} \% 15-\mathrm{nm} \mathrm{Au}$ nanoparticles dispersed on an amorphous titania support treated with a $\mathrm{NaOH}$ solution $\left(\mathrm{Au} / \mathrm{TiO}_{2}(\mathrm{~A})+\mathrm{NaOH}\right)$. Shown are features associated with $\mathrm{CO}$ (stretching $\mathrm{C}-\mathrm{O}$ mode, blueshaded area) and $\mathrm{CO}_{2}$ (red), the species relevant to the reaction, as well as with carbonate (brown) and hydroxo (purple) surface groups, which do not participate in this catalysis.

Figure 2. Full-range DRIFTS data similar to those in Figure 1 for representative $\mathrm{Au} / \mathrm{TiO}_{2}$ catalysts during reaction with $\mathrm{CO}+\mathrm{O}_{2}$ gas mixtures at $120 \mathrm{~K}$ (except for $\mathrm{b}$, which reports a reaction at $300 \mathrm{~K}$ ). The catalysts reported are: (a) $\mathrm{Au} / \mathrm{TiO}_{2}(\mathrm{~A})+\mathrm{NaOH}$ (the catalyst active at cryogenic temperatures, same as Figure 1); (b) The same $\mathrm{Au} / \mathrm{TiO}_{2}(\mathrm{~A})+\mathrm{NaOH}$, but for a reaction carried out at $300 \mathrm{~K}$; (c) $\mathrm{Au} / \mathrm{TiO}_{2}(\mathrm{~A})$; (d) $\mathrm{Au} / \mathrm{TiO}_{2}(\mathrm{~A})+\mathrm{NaOH}+\mathrm{HCl}$; and (e) $\mathrm{Au} / \mathrm{TiO}_{2^{-}}$ $\mathrm{P} 25+\mathrm{NaOH}$. These data highlight the different behavior of the catalysts in terms of the formation of surface carbonates and hydroxo groups.

Figure 3. (a) Kinetic measurements, in the form of the evolution of the integrated signals of the $\mathrm{CO}$ and $\mathrm{CO}_{2}$ DRIFTS peaks versus time, for the conversion at $120 \mathrm{~K}$ with the $\mathrm{Au} / \mathrm{TiO}_{2}(\mathrm{~A})+$ $\mathrm{NaOH}$ catalyst (estimated from spectra such as those shown in Figure 1). (b, c) Turnover frequencies (TOFs), in terms of $\mathrm{CO}_{2}$ molecules produced per $\mathrm{Au}$ surface atom per second, for the conversion of mixtures of 200 Torr $\mathrm{CO}+200$ Torr $\mathrm{O}_{2}$, calculated after $1 \mathrm{~h}$ of reaction. Reported 
are TOFs as a function of reaction temperature in the range from 120 to $400 \mathrm{~K}$ for our $\mathrm{Au} / \mathrm{TiO}_{2}(\mathrm{~A})+\mathrm{NaOH}$ catalysts as well as for a number of reference samples. Only the $\mathrm{Au} / \mathrm{TiO}_{2}(\mathrm{~A})+\mathrm{NaOH}$ catalyst displays measurable catalytic activity at cryogenic $(<250 \mathrm{~K})$ temperatures.

Figure 4. Raw DRIFTS kinetic data for the conversion of 200 Torr $\mathrm{CO}+200$ Torr $\mathrm{O}_{2}$ mixtures with different gold-titania catalysts. The integrated DRIFTS signal intensities for the peaks corresponding to $\mathrm{CO}_{2}(\mathrm{a}, \mathrm{c}, \mathrm{e})$ and $\mathrm{CO}(\mathrm{b}, \mathrm{d}, \mathrm{f})$ are reported as a function of time for our $\mathrm{Au} / \mathrm{TiO}_{2}(\mathrm{~A})$ catalyst, as prepared (c, d) and after sequential treatments with $\mathrm{NaOH}(\mathrm{a}, \mathrm{b})$ and $\mathrm{HCl}$ (e, f). Catalytic $\mathrm{CO}$ oxidation below $250 \mathrm{~K}$ is seen only with the $\mathrm{Au} / \mathrm{TiO}_{2}(\mathrm{~A})+\mathrm{NaOH}$ sample.

Figure 5. DRIFTS kinetic data similar to those in Figure 4 but for the $\mathrm{Au} / \mathrm{TiO} \mathrm{O}_{2} \mathrm{P} 25$ catalysts, as prepared (a, b), and after $\mathrm{NaOH}$ treatment (c, d). As opposed to the $\mathrm{Au} / \mathrm{TiO}_{2}(\mathrm{~A})+\mathrm{NaOH}$ sample, treatment of $\mathrm{Au} / \mathrm{TiO}_{2}-\mathrm{P} 25$ with $\mathrm{NaOH}$ does not lead to catalytic activation at cryogenic $(<250 \mathrm{~K})$ temperatures.

Figure 6. X-ray photoelectron spectroscopy (XPS) data for our gold-titania catalysts. (a) $\mathrm{Au} 4 \mathrm{f}$ XPS traces for the $1 \mathrm{wt} \% 15-\mathrm{nm} \mathrm{Au} / \mathrm{TiO}_{2}(\mathrm{~A})$ catalyst, as prepared (top, blue trace) and after sequential $\mathrm{NaOH}$ (middle, red) and $\mathrm{HCl}$ (bottom, green) treatments. (b, c) Raw (b) and differential (c) $\mathrm{Ti} 2 \mathrm{p}$ XPS traces for several gold-titania samples, including our $\mathrm{Au} / \mathrm{TiO}_{2}(\mathrm{~A})+\mathrm{NaOH}$ catalyst (3rd trace from top in Fig $2 \mathrm{~b}$, light blue). The formation of titanate sites upon treatment with $\mathrm{NaOH}$ is evidenced by the shift in some of the Ti $2 \mathrm{p}_{3 / 2}$ signal intensity 
toward a binding energy of $459.1 \mathrm{eV}$, as highlighted in the differential traces (Figure 3c). This change can be reversed upon subsequent treatment with $\mathrm{HCl}$.

Figure 7. DRIFTS kinetic evidence for the formation of the first adsorbed CO intermediate on the titania surface during the cryogenic-temperature catalytic oxidation of CO. The two panels contrast $\mathrm{CO}_{2}$ product accumulation curves versus time for reactions carried out with our $\mathrm{Au} / \mathrm{TiO}_{2}(\mathrm{~A})+\mathrm{NaOH}$ catalysts at 120 (a) versus 300 (b) $\mathrm{K}$. Results are reported from three types of experiments in each case, with 200 Torr $\mathrm{CO}+200$ Torr $\mathrm{O}_{2}$ mixtures (red traces), and where the gases are supplied sequentially (and pumped out of the system in between) in both $\mathrm{CO}-$ Pump- $\mathrm{O}_{2}$ (blue) and $\mathrm{O}_{2}-\mathrm{Pump}-\mathrm{CO}$ (green) sequences. Particularly relevant to the identification of a new cryogenic catalytic regime is the activity seen with the CO-Pump- $\mathrm{O}_{2}$ sequence at 120 but not at $300 \mathrm{~K}$.

Figure 8. (a) DRIFTS data in the $\mathrm{CO}$ and $\mathrm{CO}_{2}$ regions for a $\mathrm{CO}-\mathrm{Pump}-\mathrm{O}_{2}$ experiment with the $1 \mathrm{wt} \% 15-\mathrm{nm} \mathrm{Au} / \mathrm{TiO}_{2}(\mathrm{~A})+\mathrm{NaOH}$ catalyst at $120 \mathrm{~K}$. No DRIFTS features at all are seen after pumping the gas-phase $\mathrm{CO}$ (2nd trace from bottom, green), but a new peak appears at $\sim 2180 \mathrm{~cm}^{-1}$ once $\mathrm{O}_{2}$ is added (3rd from bottom, dark red). The $2180 \mathrm{~cm}^{-1}$ signal decreases with time as the $\mathrm{CO}$ is converted to $\mathrm{CO}_{2}\left(\sim 2350 \mathrm{~cm}^{-1}\right.$ peak). (b) Time evolution of the $\mathrm{CO}_{2}$ DRIFTS signal intensity (accumulated $\mathrm{CO}_{2}$, red) and of its derivative (TOF, green) as well as of the signal intensities of the DRIFTS peaks for CO adsorbed on gold $\left(2110 \mathrm{~cm}^{-1}\right.$, purple) and on titania $\left(2180 \mathrm{~cm}^{-1}\right.$, blue), obtained during a CO-Pump- $\mathrm{O}_{2}$ experiment at $120 \mathrm{~K}$ with a $1 \mathrm{wt} \% 3.5-\mathrm{nm}$ $\mathrm{Au} / \mathrm{TiO}_{2}(\mathrm{a})+\mathrm{NaOH}$ catalyst. To note here is the correlation seen between the reaction TOF and the DRIFTS signal intensity for the CO-titania (but not the CO-Au) surface species. (c) 
Accumulation of $\mathrm{CO}_{2}$ versus time, in the form of turnover number (TON, number of $\mathrm{CO}_{2}$ molecules per Au surface site per second), obtained in CO-Pump- $\mathrm{O}_{2}$ experiments with the series of gold-titania catalysts indicated in the figure. The activity seen with all catalysts points to the fact that the $\mathrm{NaOH}$ treatment is not required to produce $\mathrm{CO}_{2}$ in the sequential-dosing experiments. The data in Figure $8 \mathrm{~b}$ are for a catalyst with smaller Au nanoparticles than in the rest of the report, 3.5 vs. $15 \mathrm{~nm}$, because the correlation between $\mathrm{CO}$ coverage and $\mathrm{CO}_{2}$ production rate is seen more clearly with that sample, but similar behavior was observed for the other nanoparticle sizes as well.

Figure 9. DRIFTS data in the $\mathrm{C}-\mathrm{O}$ stretching $/ \mathrm{CO}_{2}$ region obtained at different stages of CO-Pump- $\mathrm{O}_{2}$ sequential experiments with different gold-titania catalysts, namely: (a) $\mathrm{Au} / \mathrm{TiO}_{2}(\mathrm{~A}) ; \quad$ (b) $\mathrm{Au} / \mathrm{TiO}_{2}(\mathrm{~A})+\mathrm{NaOH} ; \quad$ (c) $\mathrm{Au} / \mathrm{TiO}_{2}-\mathrm{P} 25 ;$ (d) $\mathrm{Au} / \mathrm{TiO}_{2}-\mathrm{P} 25+\mathrm{NaOH} ;$ (e) $\mathrm{TiO}_{2}(\mathrm{~A})+\mathrm{NaOH}$; and (f) $\mathrm{Au} / \mathrm{TiO}_{2}(\mathrm{~A})+\mathrm{NaOH}+\mathrm{HCl}$. The appearance of the $\sim 2180 \mathrm{~cm}^{-1}$ adsorbed $\mathrm{CO}$ species after introduction of $\mathrm{O}_{2}$ to the reaction chamber is seen in all cases (although to a lesser extent in the case of the pure titania support, Figure 9e), indicating that this intermediate forms on the titania, not on the gold, surface.

Figure 10. DRIFTS evidence for the formation of a second CO-titania intermediate during the cryogenic-temperature steady oxidation of $\mathrm{CO}$ with $\mathrm{O}_{2}$ on our $\mathrm{Au} / \mathrm{TiO}_{2}(\mathrm{~A})+\mathrm{NaOH}$ catalyst. (a) DRIFTS data in the $\mathrm{C}-\mathrm{O}$ stretching region, after subtraction of the signal from gas-phase $\mathrm{CO}$, for different gold-titania catalysts. In most cases the dominant feature is the peak at $2180 \mathrm{~cm}^{-1}$, but in the case of our $\mathrm{Au} / \mathrm{TiO}_{2}(\mathrm{~A})+\mathrm{NaOH}$ (2nd from bottom, red), the only catalyst that promotes $\mathrm{CO}$ oxidation at $120 \mathrm{~K}$, the $2180 \mathrm{~cm}^{-1}$ feature is replaced by a strong peak at $2160 \mathrm{~cm}^{-1}$. (b, c) 
$\mathrm{CO}$ and $\mathrm{CO}_{2}$ DRIFTS data as a function of reaction time (b, for the $1 \mathrm{wt} \% 15-\mathrm{nm}$ $\mathrm{Au} / \mathrm{TiO}_{2}(\mathrm{~A})+\mathrm{NaOH}$ catalyst) and of gold nanoparticle size (c) during the steady conversion of $\mathrm{CO}+\mathrm{O}_{2}$ mixtures at $120 \mathrm{~K}$. The $\mathrm{CO}$ peaks have been deconvoluted into their 2160 and 2180 $\mathrm{cm}^{-1}$ components to aid in their analysis. In both cases, the changes associated with $\mathrm{CO}_{2}$ production are seen only in the first $\left(2160 \mathrm{~cm}^{-1}\right)$ feature.

Figure 11. Schematic representation of the proposed cryogenic-temperature CO oxidation mechanism, highlighting the sequential formation of the two adsorbed CO-titania species identified in these studies and the synergistic effect of $\mathrm{O}_{2}$ in the uptake of $\mathrm{CO}$ on the surface. 


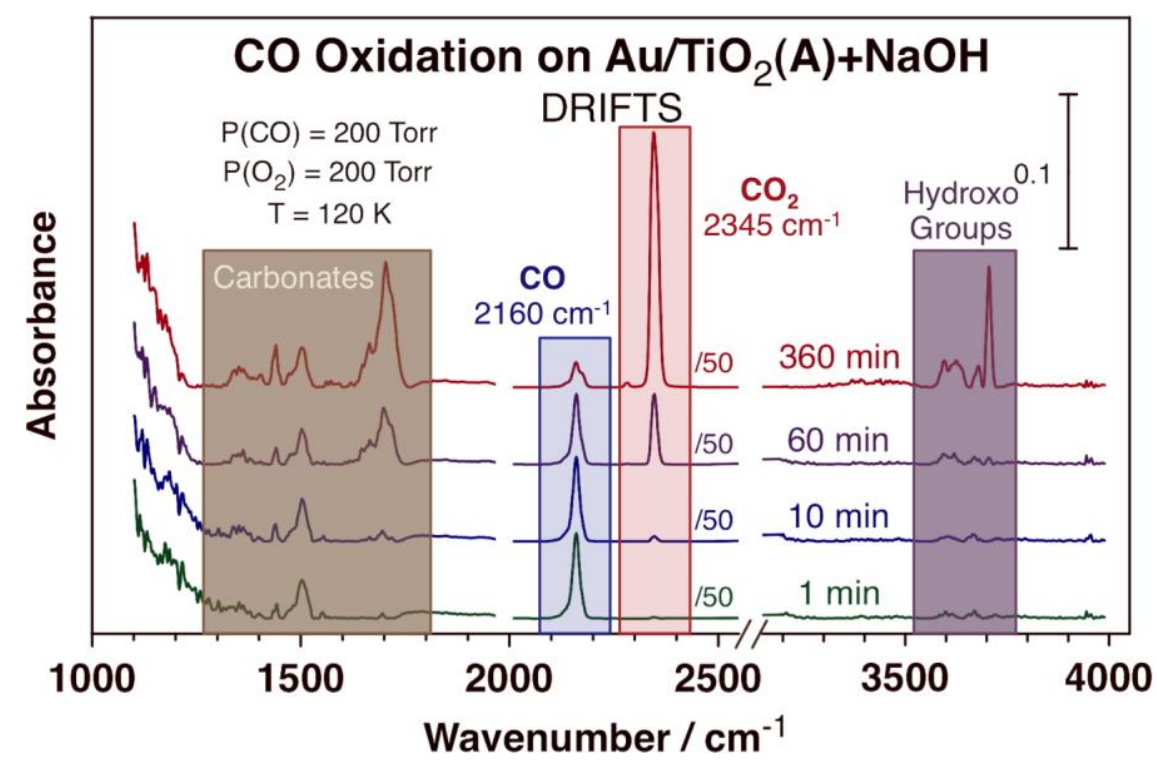

Figure 1 

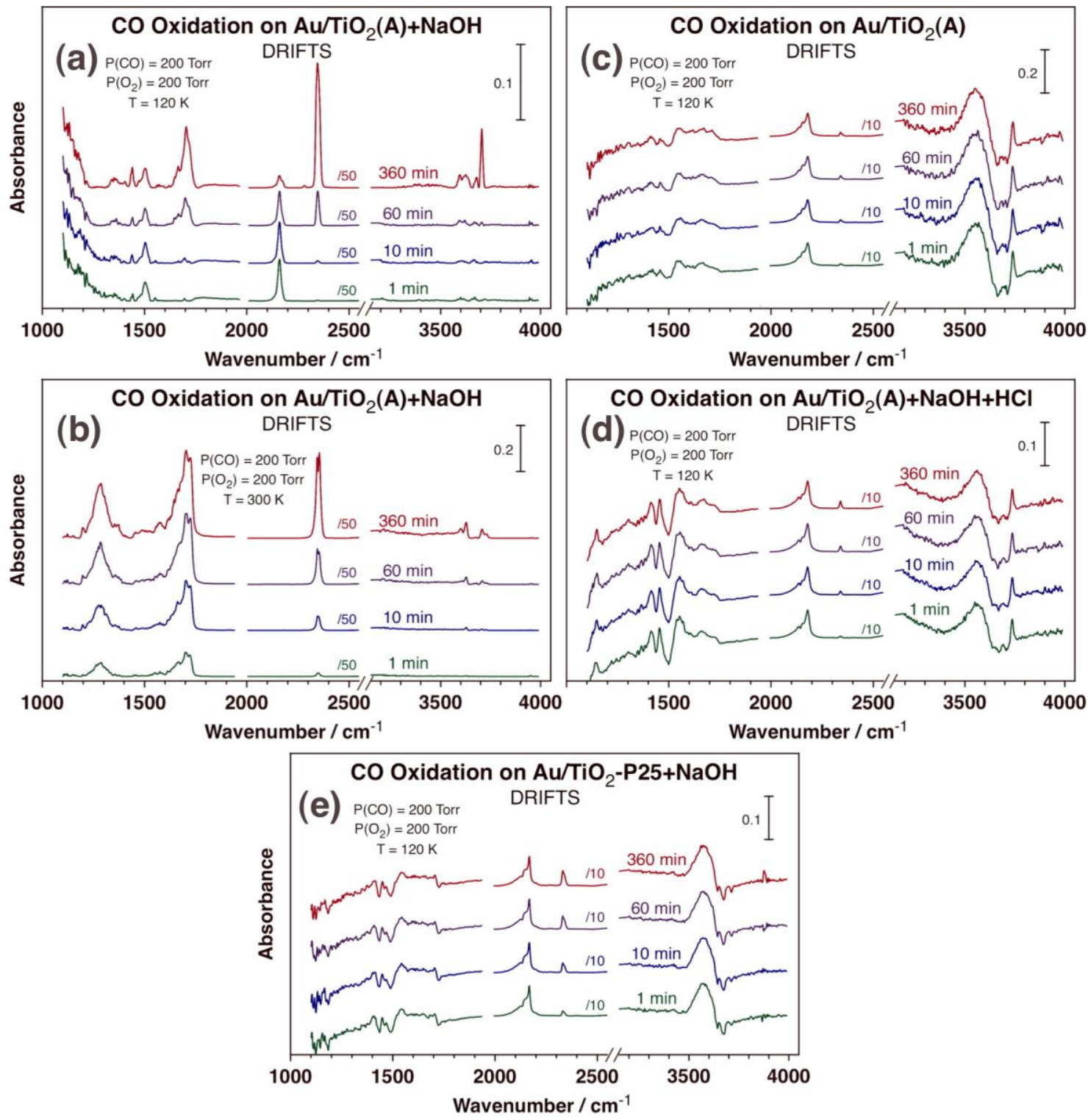

Figure 2 

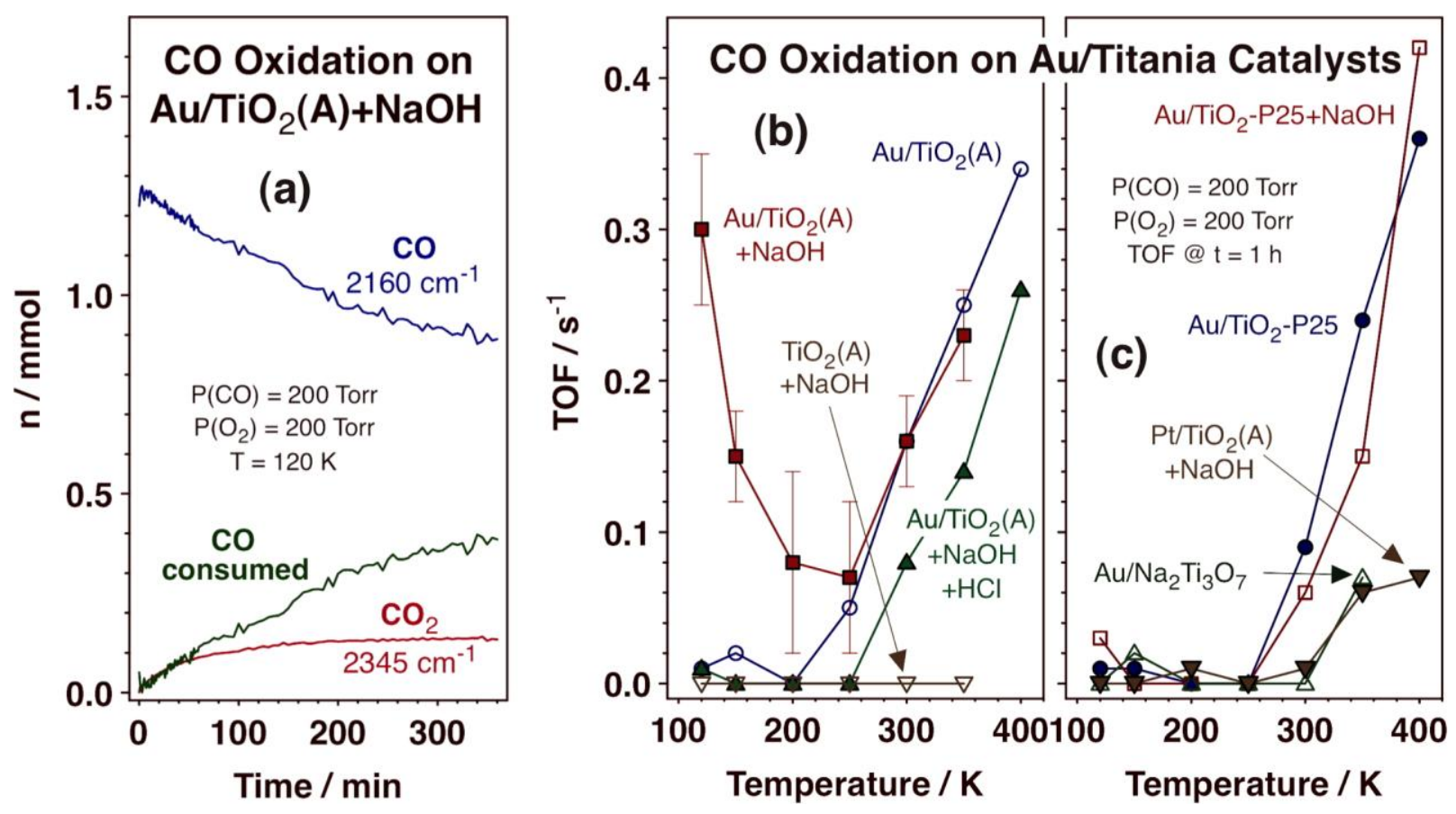

Figure 3 

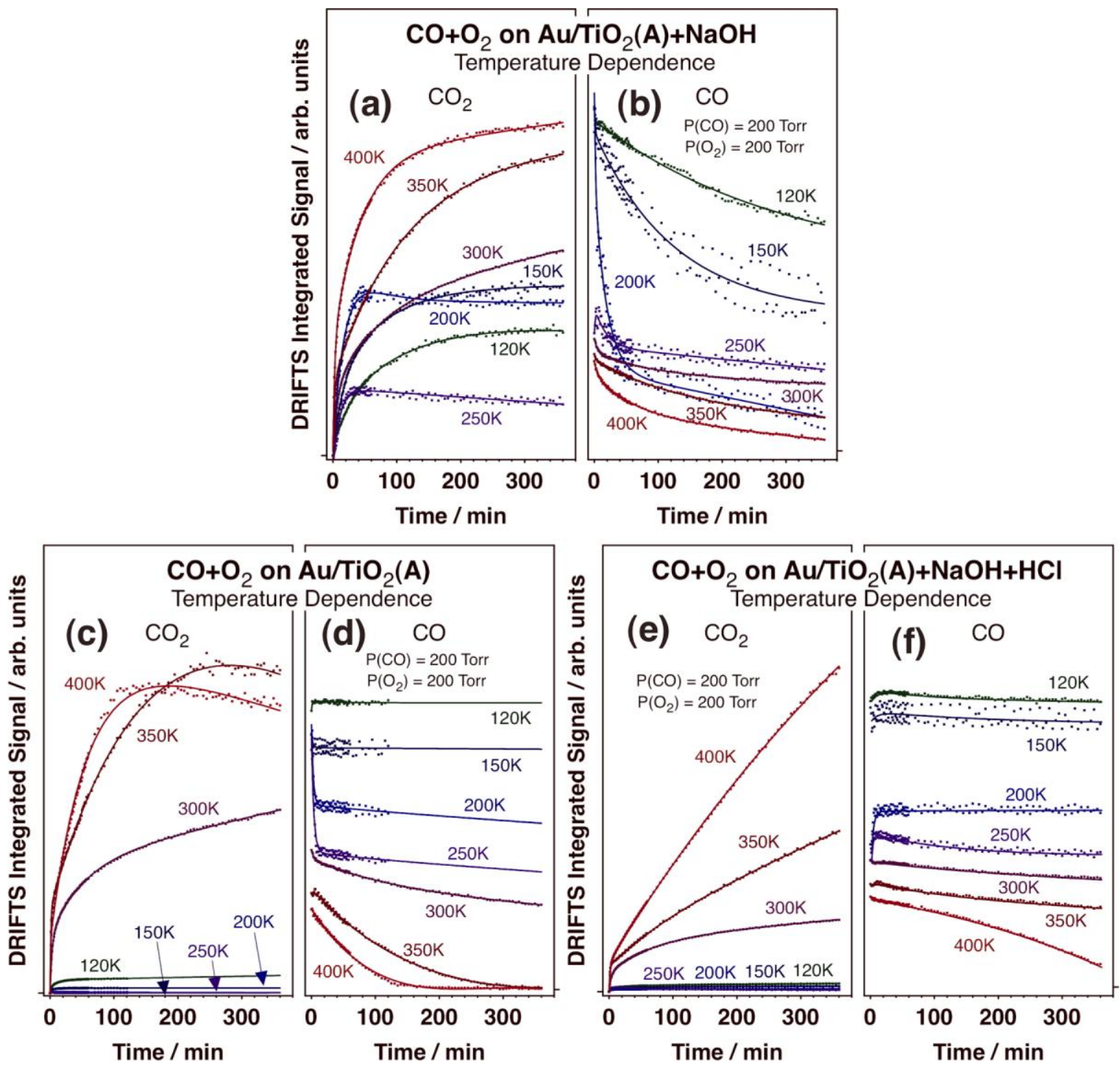

Figure 4 

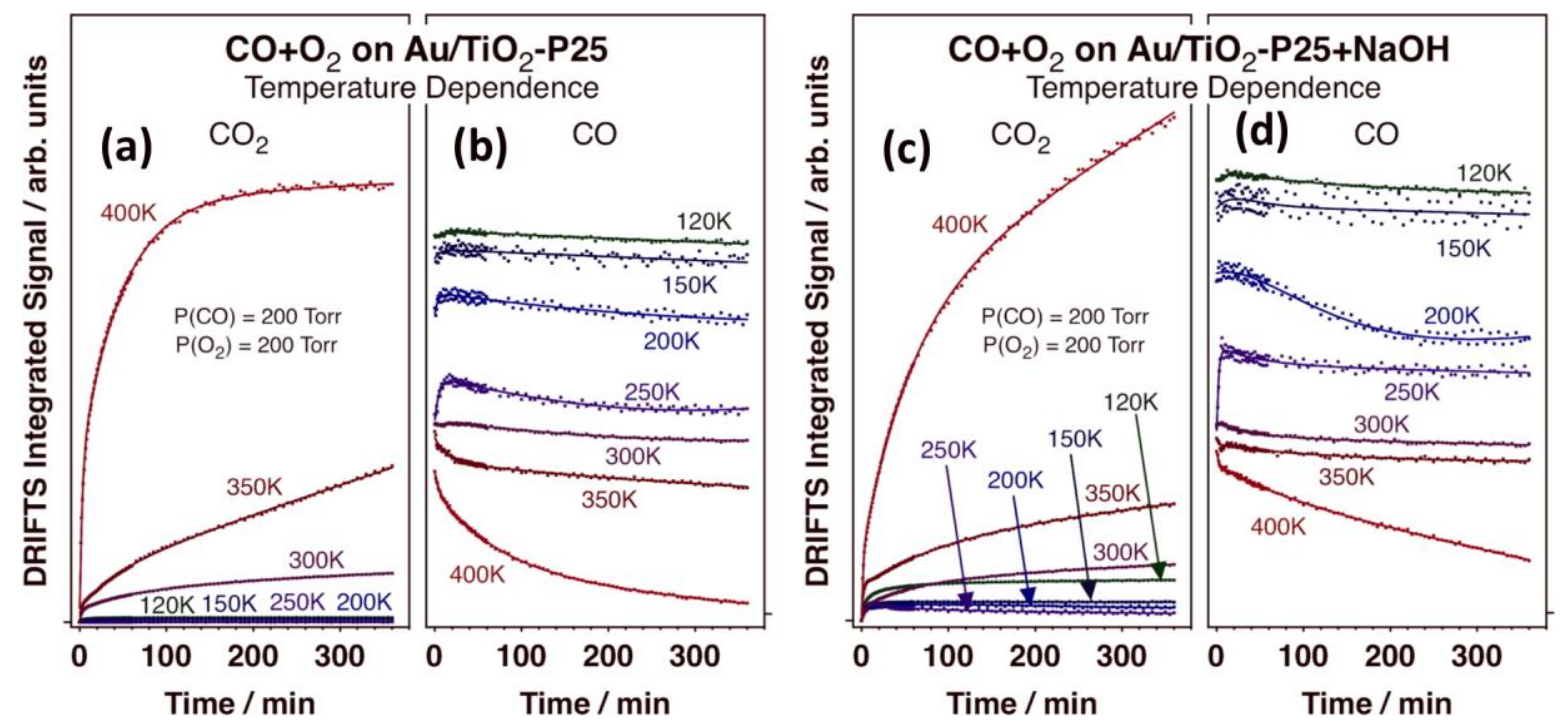

Figure 5 

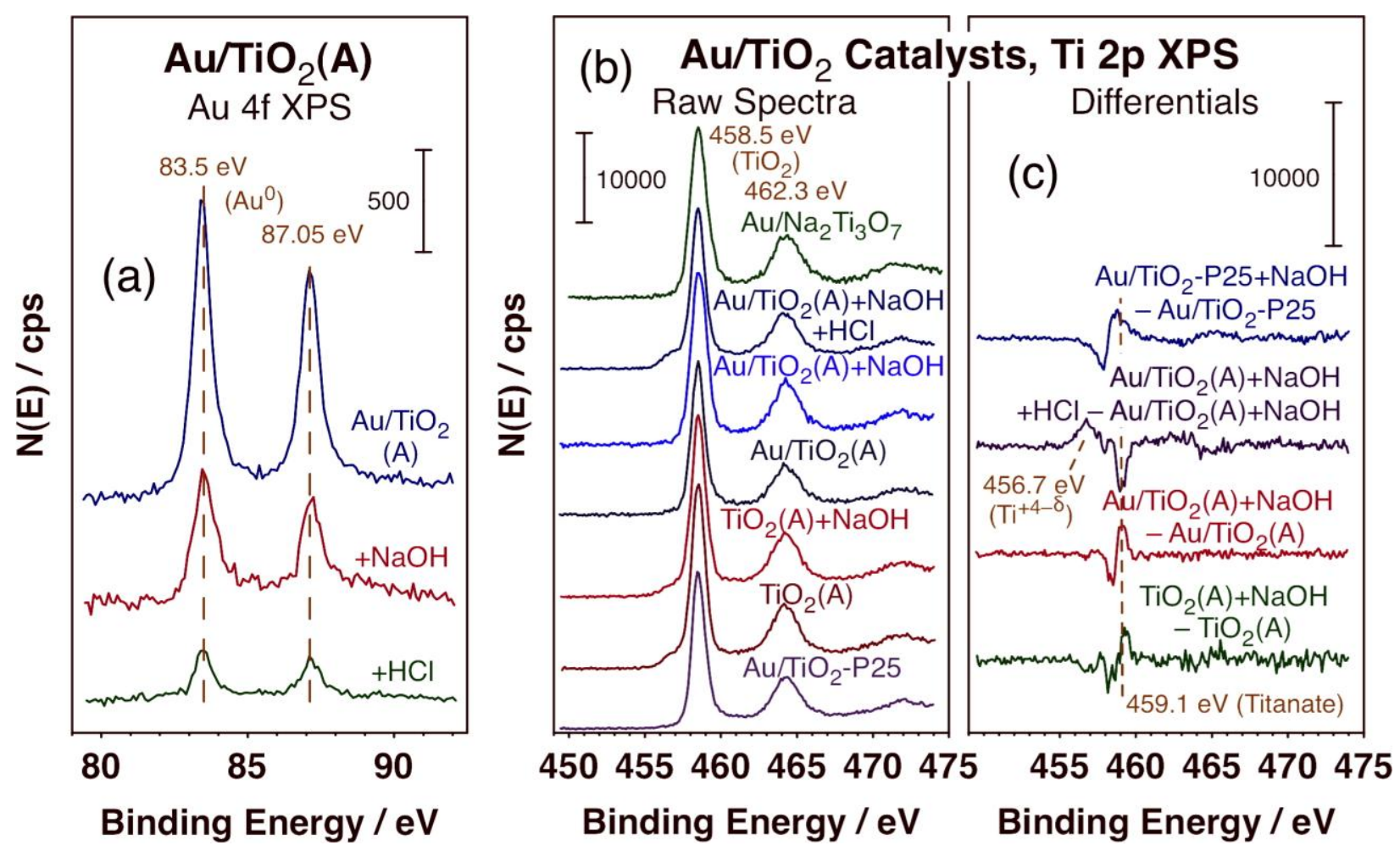

Figure 6 


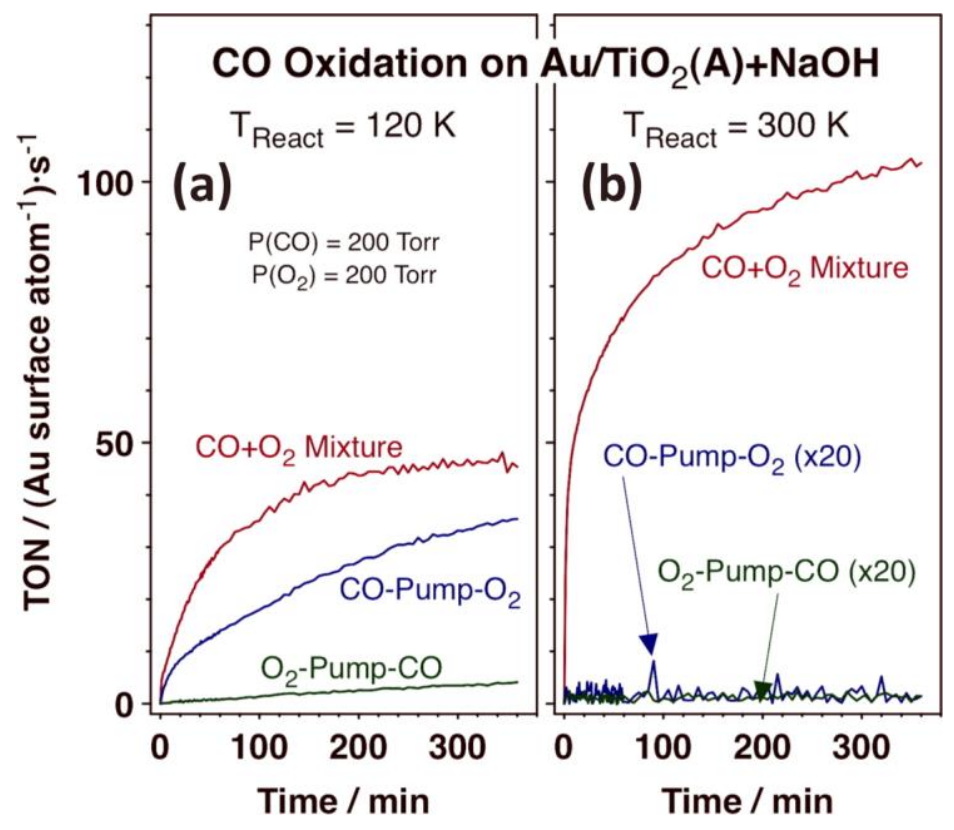

Figure 7 

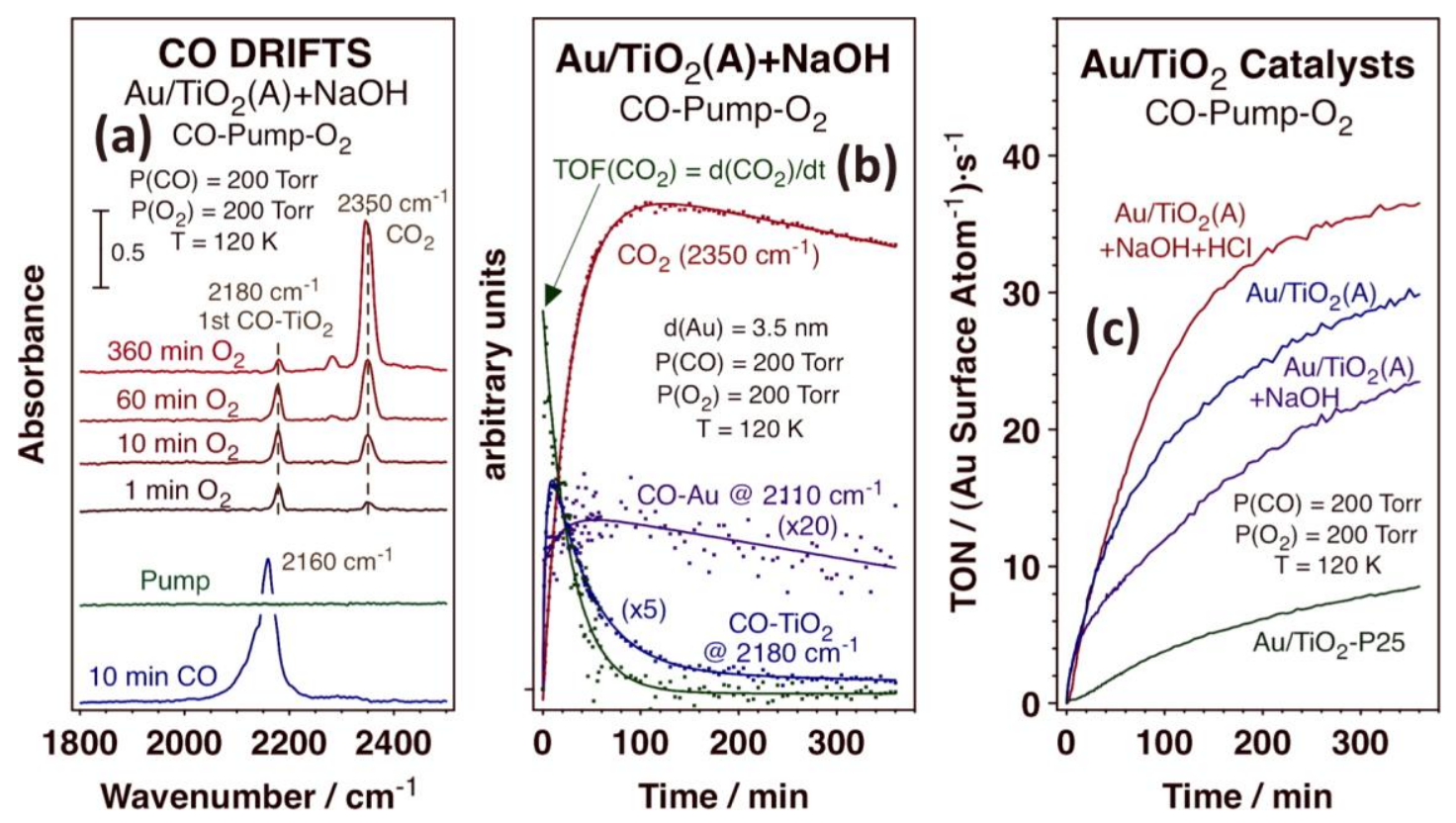

Figure 8 


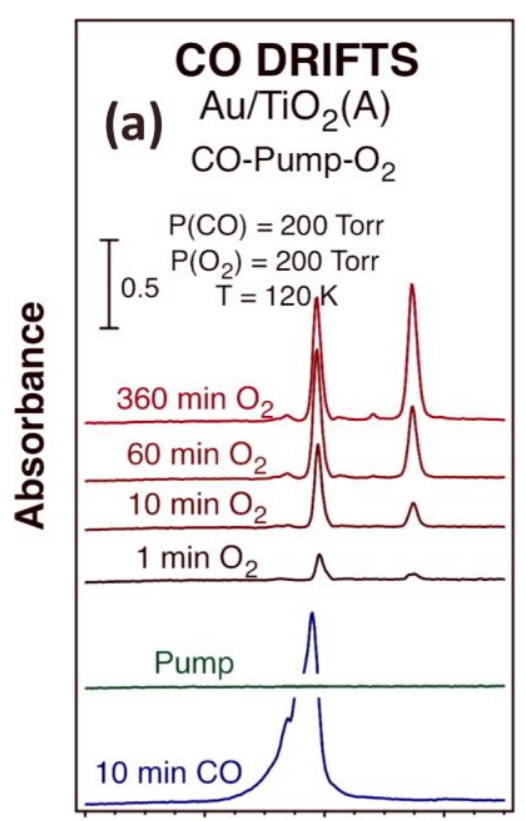

CO DRIFTS

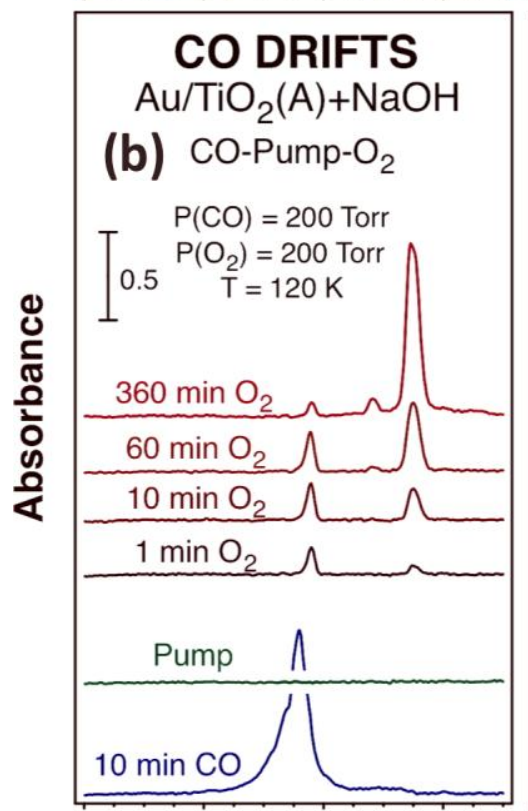

1800200022002400

Wavenumber $/ \mathrm{cm}^{-1}$
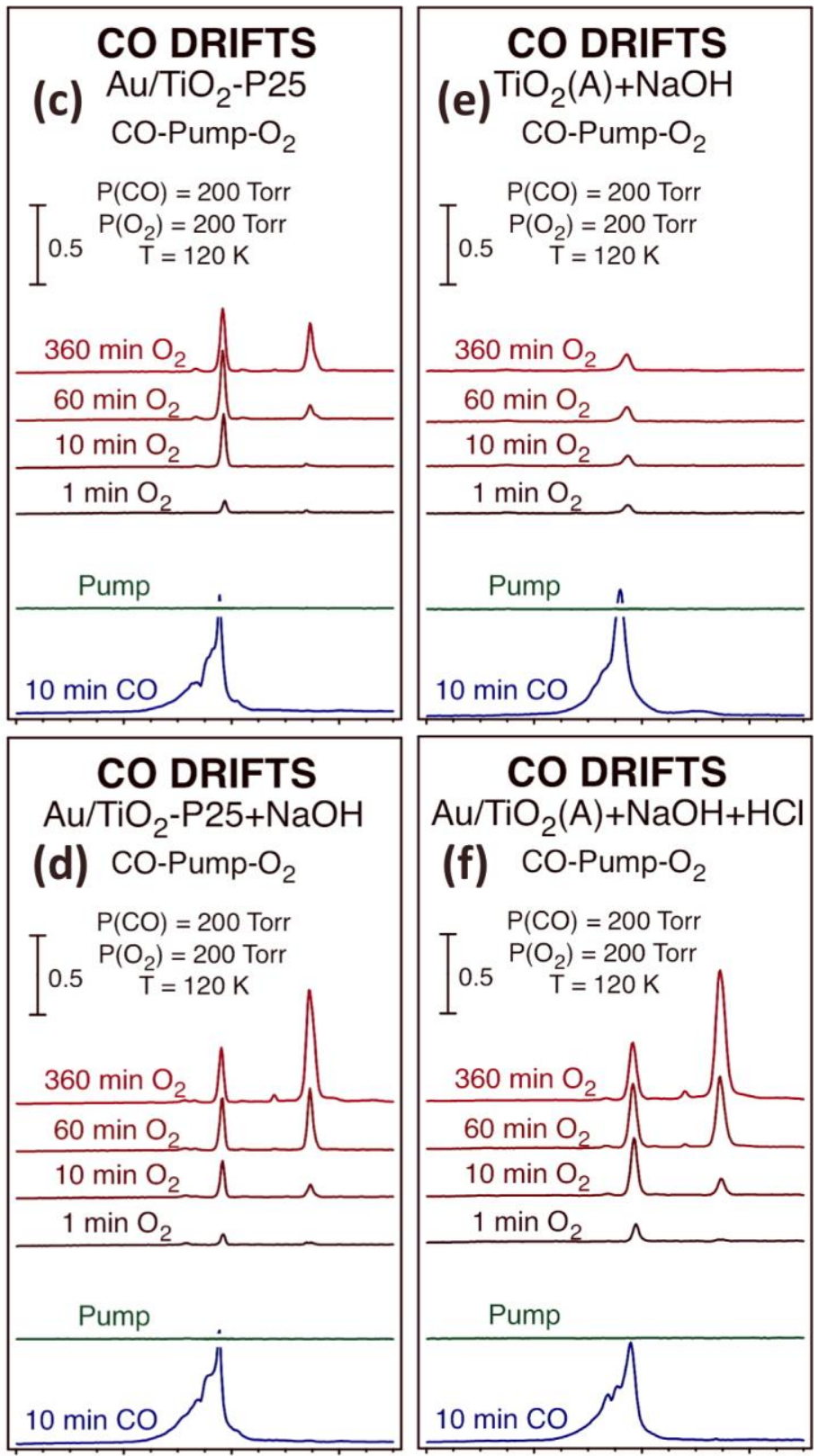

800200022002400

Wavenumber $/ \mathrm{cm}^{-1}$

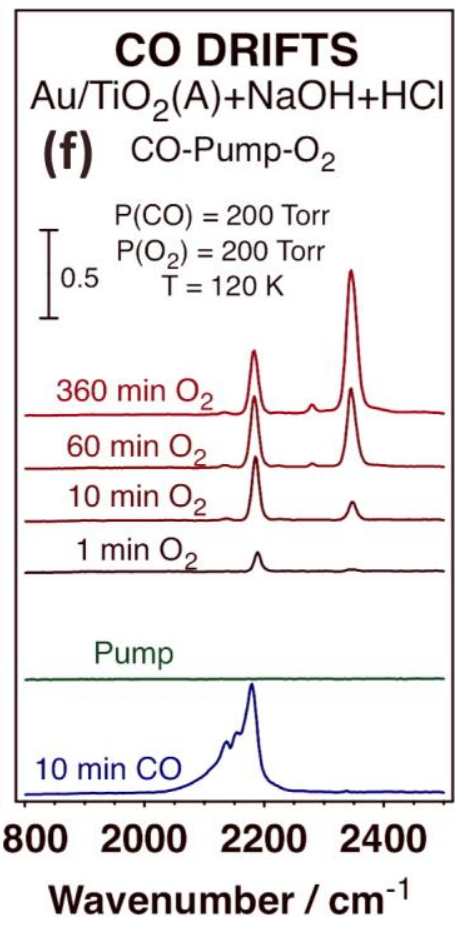

Figure 9 


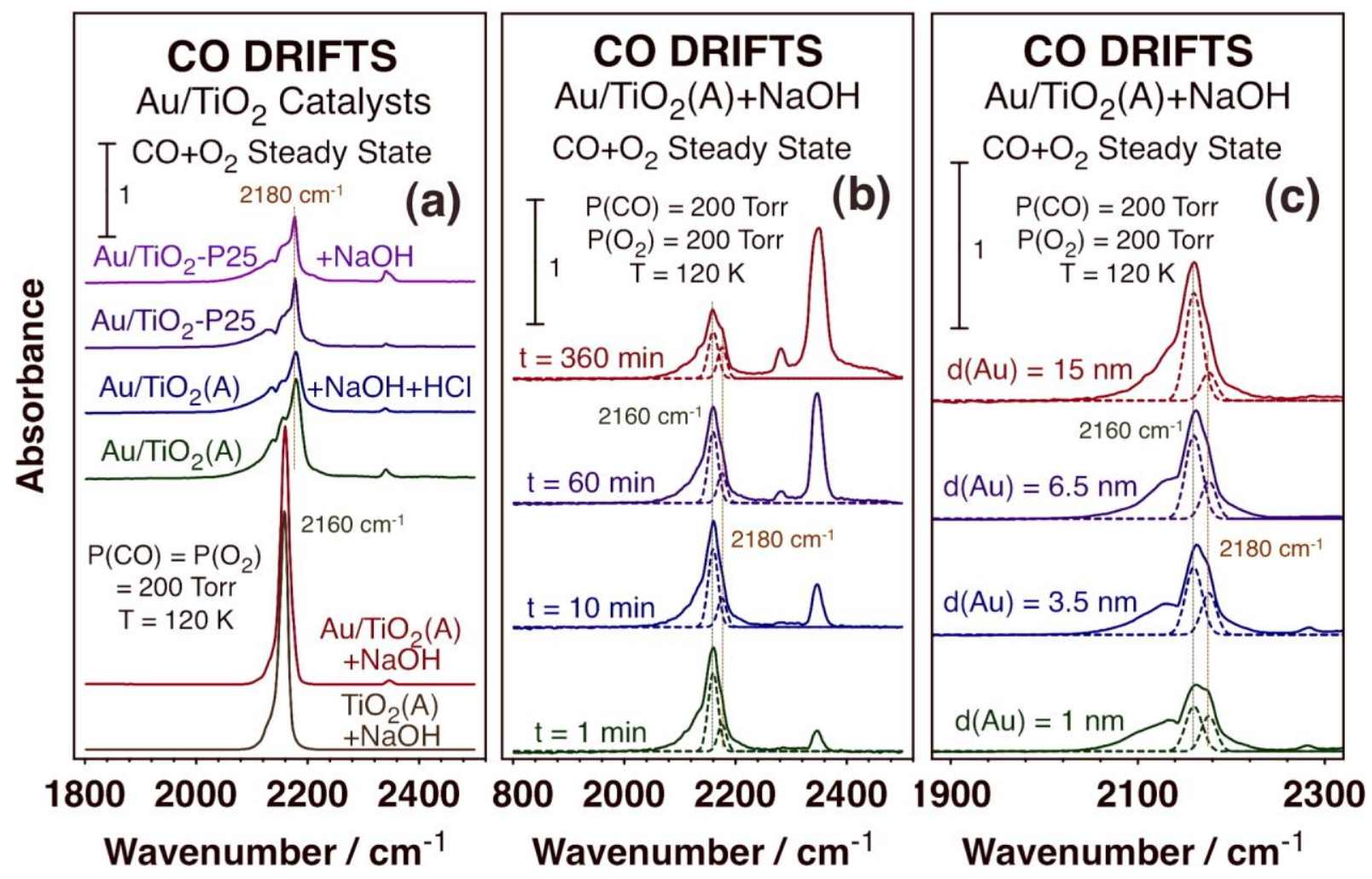

Figure 10 


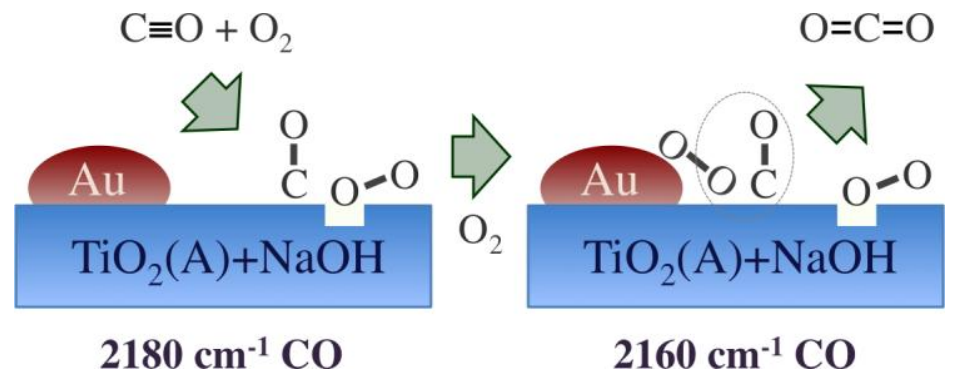

Figure 11 

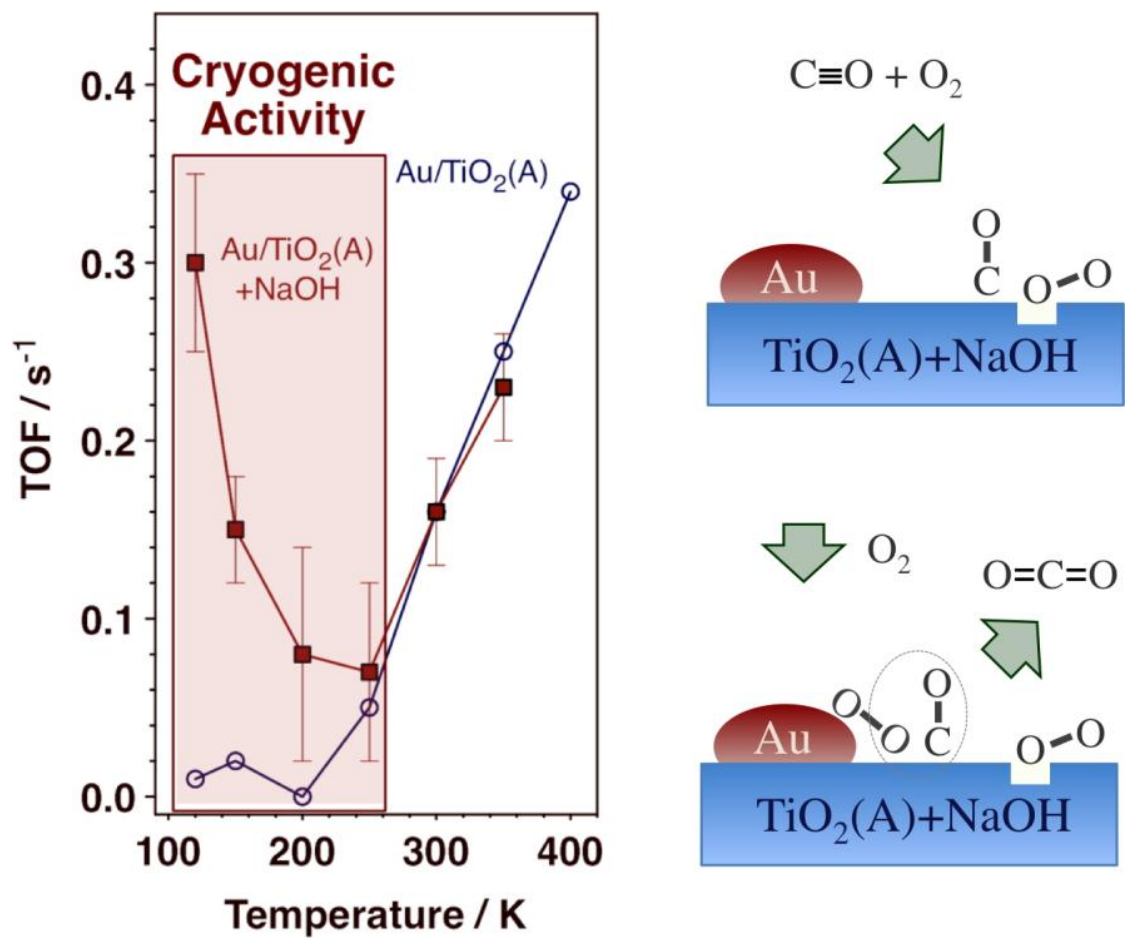

TOC Graphics 